Check for updates

Cite this: RSC Adv., 2017, 7, 50264

\title{
Simple method for simultaneously achieving red and green up-conversion luminescence $\uparrow$
}

\author{
Xiumei Yin, Hong Wang, Mingming Xing, Yao Fu, Ying Tian and Xixian Luo (D)*
}

The simultaneous emission of red and green light with high brightness and color purity was obtained from $\mathrm{Er}^{3+}$-doped $\mathrm{NaYbF}_{4}$-based up-conversion nanoparticles excited by 980 and $1550 \mathrm{~nm}$ excitation. The ${ }^{2} \mathrm{~F}_{5 / 2}$ level of $\mathrm{Yb}^{3+}$ showed high absorption efficiency at $980 \mathrm{~nm}$. The ${ }^{4} \mathrm{I}_{13 / 2}$ level of $\mathrm{Er}^{3+}$, an excellent UC intermediate with high energy and a long lifetime (milliseconds), absorbed more energy in the cross section $\left(6.0 \times 10^{-20} \mathrm{~cm}^{2}\right)$ than did the $\mathrm{Yb}^{3+}{ }^{2} \mathrm{~F}_{5 / 2}$ level $\left(1.2 \times 10^{-20} \mathrm{~cm}^{2}\right)$ and was efficiently and directly pumped by light with a wavelength of $\sim 1500 \mathrm{~nm}$. In contrast to particles resulting from other methods using complex coating for achieving multi-color emission in a single sample, the as-prepared luminescent $\mathrm{NaYbF}_{4}: 25 \% \mathrm{Er}^{3+}$ up-conversion nanoparticles were designed to be single-layered and spherical and showed excellent dispersibility and uniform sizes. Nanoparticles prepared by this method exhibit a great advantage based on the simple preparation process and small particle size. On this basis, we expect to easily achieve the emission of three primary colors by these reasonably designed core-shell particles.

Received 23rd August 2017

Accepted 19th October 2017

DOI: 10.1039/c7ra09330f

rsc.li/rsc-advances
$\mathrm{NaYF}_{4}$ up-conversion nanoparticles (UCNPs) with a five-layer core-shell structure to obtain blue-green two-color emission under excitation with light of wavelengths of 980 and $808 \mathrm{~nm}^{21}$ Deng et al. ${ }^{22}$ designed an unsteady UC full-color luminescence in $\mathrm{NaYF}_{4}$ UCNPs with a five-layer core-shell structure by adjusting the pulse width. These UCNPs realize multi-color emission but require a relatively complex preparation process and large particle size. Consequently, there is an urgent need to obtain a simple method for realizing multi-color emission.

Green and red double color UCL has been realized in micronsized single $\mathrm{Y}_{2} \mathrm{O}_{2} \mathrm{~S}: \mathrm{Yb}^{3+}, \mathrm{Er}^{3+} \mathrm{UC}$ materials under 980 and $1550 \mathrm{~nm}$ dual wavelength excitation. ${ }^{23} \mathrm{Yb}^{3+}$ and $\mathrm{Er}^{3+}$ ions form two sensitization systems excited at 980 and $1550 \mathrm{~nm}$, respectively, and exhibit different UCL characteristics. In the current work, $\mathrm{NaYbF}_{4}: 25 \% \mathrm{Er}^{3+}$ UCNPs were shown to simultaneously emit red and green light when excited with light of wavelengths of 980 and $1550 \mathrm{~nm}$.

\section{Experimental}

\subsection{Materials}

All materials purchased were used as described below without further purification. 1-Octadecene (OM; 90\%), oleic acid (OA; $90 \%), \mathrm{Y}\left(\mathrm{CH}_{3} \mathrm{COO}\right)_{3} \cdot 4 \mathrm{H}_{2} \mathrm{O}, \mathrm{Yb}\left(\mathrm{CH}_{3} \mathrm{COO}\right)_{3}$, and $\mathrm{Er}\left(\mathrm{CH}_{3} \mathrm{COO}\right)_{3}$ were purchased from Alfa Aesar. Ammonium fluoride $\left(\mathrm{NH}_{4} \mathrm{~F}\right)$, sodium hydroxide $(\mathrm{NaOH})$, methanol, cyclohexane, and ethanol were purchased from Tianjinzhiyuan Chemical Reagent Co and used as received. For each experiment, $\mathrm{Re}\left(\mathrm{CH}_{3} \mathrm{COO}\right)_{3}$ was dissolved in deionized water, and $\mathrm{NaOH}$ and $\mathrm{NH}_{4} \mathrm{~F}$ were dissolved in methanol solution in advance to reduce the experimental error. 


\subsection{Synthesis of $\mathrm{NaYbF}_{4}: x \mathrm{Er}^{3+}(x=10,25,50,90 \mathrm{~mol} \%)$}

A volume of $3 \mathrm{~mL}$ of oleic acid and a volume of $7 \mathrm{~mL}$ of octadecene were added, respectively, to two vials by using a two-way valve, and a volume of $2 \mathrm{~mL}(0.4 \mathrm{mmol})$ of $\mathrm{Re}\left(\mathrm{CH}_{3} \mathrm{COO}\right)_{3}(0.2 \mathrm{M})$ was added in proportion $(\mathrm{Yb}=0.36,0.3,0.2,0.04 \mathrm{mmol}$, as $\mathrm{Er}=$ $0.04,0.1,0.2,0.36 \mathrm{mmol}$, respectively). A thermometer able to measure temperatures between 0 and $360^{\circ} \mathrm{C}$ was inserted into each solution to precisely measure the temperature. The samples became pale yellow after being heating to $150{ }^{\circ} \mathrm{C}$ and kept at this temperature for $45 \mathrm{~min}$, and a rare earth oleate precursor solution was obtained as the sample was cooled to room temperature. Methanol solutions of $\mathrm{NaOH}(1 \mathrm{~mL}, 1 \mathrm{M})$ and $\mathrm{NH}_{4} \mathrm{~F}$ ( $4 \mathrm{~mL}, 0.4 \mathrm{M}$ ) were added to the respective flasks, and kept at $50{ }^{\circ} \mathrm{C}$ for $40 \mathrm{~min}$. The temperature was then increased to $100{ }^{\circ} \mathrm{C}$ in a vacuum environment in order to remove the methanol from the mixtures. Each solution was quickly heated (15 min) to $290^{\circ} \mathrm{C}$ under an argon environment and then, when bubbles were no longer produced, kept warm at $290^{\circ} \mathrm{C}$ for $1.5 \mathrm{~h}$, and desired product was obtained as the solution was cooled to room temperature. A volume of $8 \mathrm{~mL}$ of an ethanol solution was added to each solution, and the resulting mixture was centrifuged at $9000 \mathrm{rad}$ per min for $6 \mathrm{~min}$. The resulting product in each case was dissolved in $4 \mathrm{~mL}$ of cyclohexane and $8 \mathrm{~mL}$ of ethanol, and the resulting solution was centrifuged at $9000 \mathrm{rad}$ per min for $6 \mathrm{~min}$. The previous step was then repeated with $4 \mathrm{~mL}$ of ethanol and $4 \mathrm{~mL}$ of methanol instead of $8 \mathrm{~mL}$ of ethanol. The resulting sample in each case was dissolved in $5 \mathrm{~mL}$ of cyclohexane and sealed and stored in a glass vial at $4{ }^{\circ} \mathrm{C}$.

\subsection{Characterizations}

The size and morphology of each sample were determined by performing JEM-2100F high-resolution transmission electron microscopy (HRTEM). The UCL spectra were acquired by using an Edinburgh FS5 fluorescence spectrometer, and powertunable $980 \mathrm{~nm}$-wavelength (maximum power: $800 \mathrm{~mW}$ ) and $1550 \mathrm{~nm}$-wavelength (maximum power: $800 \mathrm{~mW}$ ) laser diodes (LDs) were used as excitation sources.

\section{Results and discussion}

${ }^{4} \mathrm{I}_{11 / 2}$ of $\mathrm{Er}^{3+}$ was pumped directly by light with a wavelength of $\sim 980 \mathrm{~nm}$ due to the relatively large energy absorption section $\left(1.7 \times 10^{-21} \mathrm{~cm}^{2}\right)$ and millisecond-range lifetime of the ${ }^{4} \mathrm{I}_{11 / 2}$ level. ${ }^{23}$ In addition, the ${ }^{4} \mathrm{I}_{13 / 2}$ level of $\mathrm{Er}^{3+}$ was found in the current work to be an excellent UC intermediate energy level with a long lifetime, and with an energy absorption cross section $\left(6.0 \times 10^{-20} \mathrm{~cm}^{2}\right)$ much larger than that of the $\mathrm{Yb}^{3+2} \mathrm{~F}_{5 / 2}$ level $\left(1.2 \times 10^{-20} \mathrm{~cm}^{2}\right)$ and that was efficiently pumped by light with a wavelength of $\sim 1500 \mathrm{~nm}$. Therefore, a high UCL efficiency was achieved using $\mathrm{Er}^{3+}$ ions as the activator with 980 and $1550 \mathrm{~nm}$ dual-wavelength excitation. ${ }^{24}$ An efficient single red UCL was easily obtained at $1500 \mathrm{~nm}$-wavelength excitation relying on the non-radiative ${ }^{4} \mathrm{I}_{9 / 2} \rightarrow{ }^{4} \mathrm{I}_{11 / 2}$ relaxation, which is based on the relatively short lifetime (10 microseconds) of $\mathrm{Er}^{3+}$ ions and small energy gap between ${ }^{4} \mathrm{I}_{9 / 2}$ and ${ }^{4} \mathrm{I}_{11 / 2}$ levels $(\Delta E \approx$ $\left.1900 \mathrm{~cm}^{-1}\right) .{ }^{25,26}$ Fig. 3a and $\mathrm{b}$ are the main green and red double-

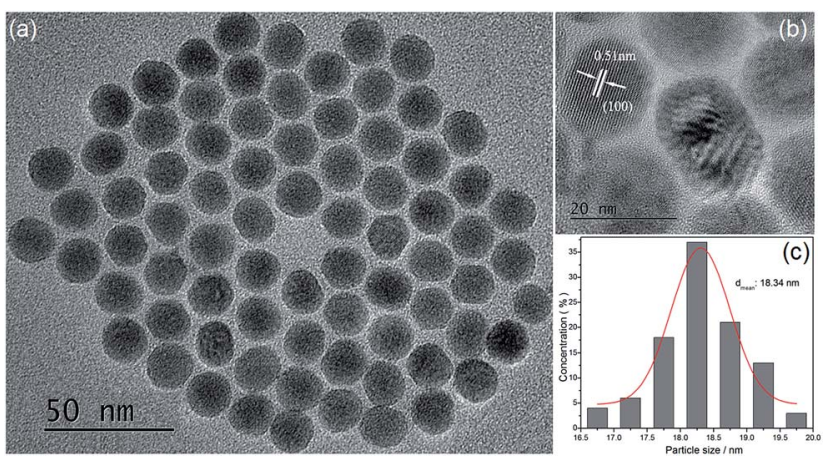

Fig. 1 (a), (b) HRTEM images and (c) corresponding particle size histograms of $\mathrm{NaYbF}_{4}: 25 \% \mathrm{Er}^{3+}$.

color UCL mechanism of $\mathrm{Y}_{2} \mathrm{O}_{2} \mathrm{~S}: \mathrm{Yb}^{3+}, \mathrm{Er}^{3+} \mathrm{UC}$ materials under 980 and $1550 \mathrm{~nm}$ dual-wavelength excitation. However, the opposite is the case for the $\beta-\mathrm{NaYF}_{4}$ host, as $\beta-\mathrm{NaYF}_{4}: \mathrm{Er}^{3+}$ (ref. 27 and 28) and $\mathrm{LiYF}_{4}: \mathrm{Er}^{3+}$ (ref. 29) show yellow-green UCL when excited at a wavelength of $1500 \mathrm{~nm}$. This condition remains unchanged even upon adding $\mathrm{Yb}^{3+}$ ions (Fig. S1 $\mathrm{f}^{\dagger}$ ), and highcolor-purity emission of red light is difficult to obtain from the $\beta-\mathrm{NaYF}_{4}$ host. Therefore, in this work, spherical $\mathrm{NaYbF}_{4}: x \%$ $\mathrm{Er}^{3+}$ UCNPs (Fig. 1), with an average particle size of $18.34 \mathrm{~nm}$, were prepared through co-precipitation. The distance between adjacent lattice planes of this product was measured using the HRTEM images to be about $0.51 \mathrm{~nm}$, which confirmed the product to be $\beta$-phase $\mathrm{NaYbF}_{4}$ (Fig. 1b).

$\mathrm{NaYbF}_{4}: x \% \mathrm{Er}^{3+}$ showed different luminescence properties with different $\mathrm{Er}^{3+}$ doping concentrations and presented distinct emission colors under excitation with wavelengths of $980 \mathrm{~nm}$ and $1550 \mathrm{~nm}$ (Fig. S1 $\dagger$ ). Under excitation at $980 \mathrm{~nm}, \mathrm{NaYbF}_{4}: 10 \%$ $\mathrm{Er}^{3+}$ showed green UCL with a red-to-green emission ratio $\left(I_{\mathrm{r}} / I_{\mathrm{g}}\right)$ of 0.59 (Fig. S1a $\dagger$ ) and $\mathrm{NaYbF}_{4}: 25 \% \mathrm{Er}^{3+}$ showed red UCL, specifically at $654 \mathrm{~nm}\left(I_{\mathrm{r}} / I_{\mathrm{g}}=3.29\right.$, Fig. 2), whereas $\mathrm{NaYbF}_{4}: 50 \%$ $\mathrm{Er}^{3+}$ exhibited decreased red UCL color purity $\left(I_{\mathrm{r}} / I_{\mathrm{g}}=2.19\right.$, Fig. S1 $\dagger$ ) and exhibited luminescence quenching. However, Wei et al. ${ }^{30}$ reported that $\mathrm{NaYbF}_{4}: 50 \mathrm{~mol}_{0} \mathrm{Er}^{3+}$ exhibits the optimal red UCL performance when excited with light at a wavelength of $980 \mathrm{~nm}$, this condition is mainly resulted from the large particle size $(\sim 100 \mathrm{~nm})$ and crystallinity (Fig. $\mathrm{S} 2 \dagger) . \mathrm{NaYbF}_{4}: x \mathrm{Er}^{3+}$ excited at $1550 \mathrm{~nm}$ showed a constant green UCL (Fig. S1b†) and exhibited the optimal emission characteristics when the doping concentration of $\mathrm{Er}^{3+}$ was $25 \mathrm{~mol} \%\left(I_{\mathrm{r}} / I_{\mathrm{g}}=0.45\right.$, Fig. 2). Therefore, emission of both red and green light with high brightness and color purity was achieved using $\mathrm{NaYbF}_{4}: 25 \% \mathrm{Er}^{3+}$ subjected to dual-wavelength excitation, at 980 and $1500 \mathrm{~nm}$; the corresponding CIE chromaticity coordinates were determined to be $(0.62,0.31)$ and $(0.29,0.64)$, respectively. The double-color UCL samples prepared by this method were each shown to have a simple structure and small particle size, and the preparation process was simple and easily controlled. Multi-color emission was achieved by adjusting the relative intensities of the two lasers (Fig. 2b).

The red and green UCL displayed by $\mathrm{NaYbF}_{4}: 25 \% \mathrm{Er}^{3+}$ under 980 and $1550 \mathrm{~nm}$-wavelength excitation was attributed to different interaction mechanisms between $\mathrm{Yb}^{3+}$ and $\mathrm{Er}^{3+}$ excited 

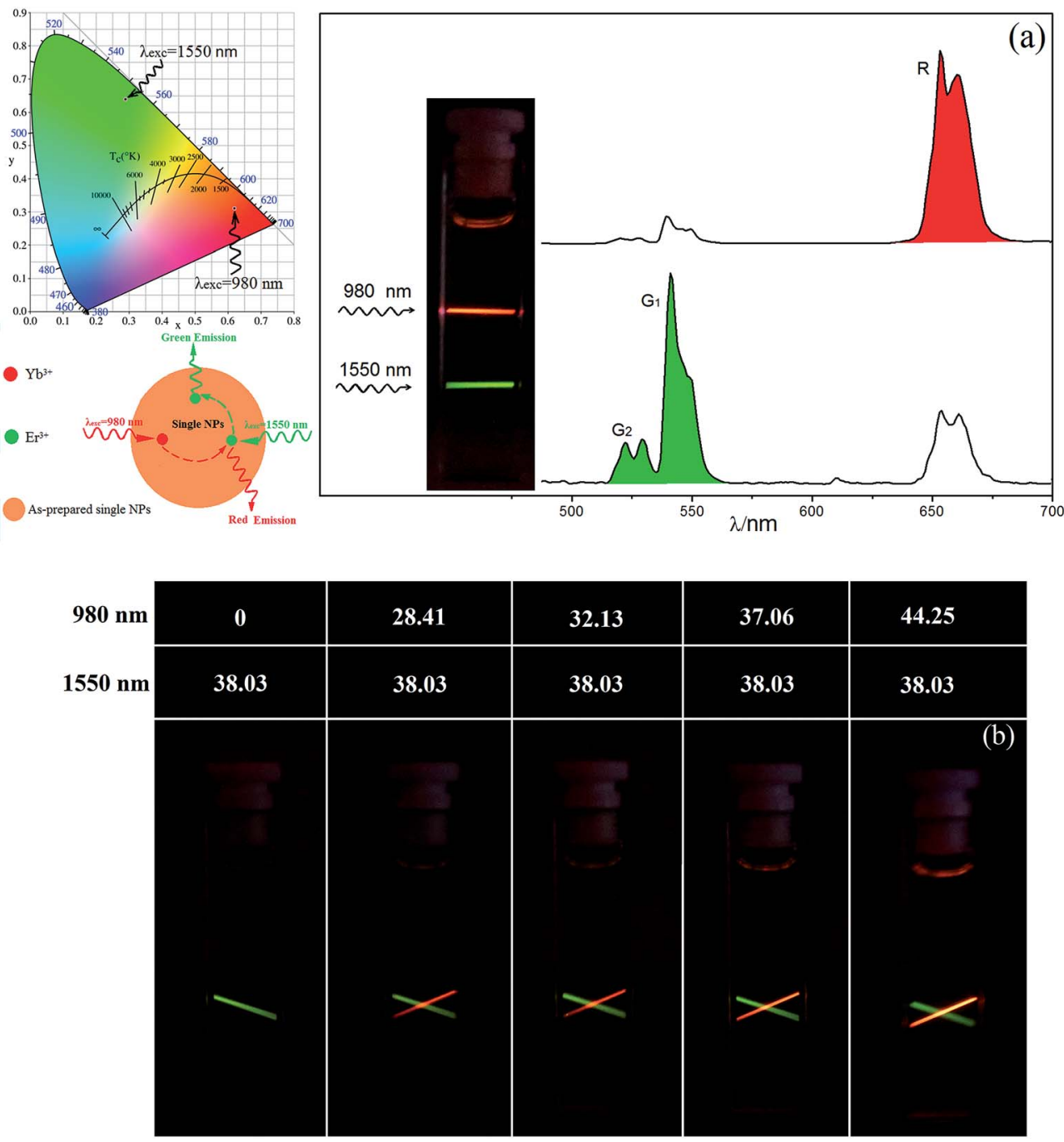

Fig. 2 (a) $\mathrm{ClE}$ chromaticity coordinates, UCL spectra, and digital camera images of $\mathrm{NaYbF}_{4}: 25 \% \mathrm{Er}^{3+}$ under 980 and $1500 \mathrm{~nm}$ wavelength excitation. (b) Multi-color emission images of $\mathrm{NaYbF}_{4}: 25 \% \mathrm{Er}^{3+}$ under excitation with wavelengths of $980 \mathrm{~nm}$ (excitation power density $=0$, 28.41, 32.13, 37.06, $44.52 \mathrm{~mW} \mathrm{~mm}^{-2}$ ) and $1550 \mathrm{~nm}$ (excitation power density $=38.03 \mathrm{~mW} \mathrm{~mm}^{-2}$ ) (Canon EOS 5D Mark III, TV $=1: 1250$, Len: EF24-70 mm f/2.8 L II USM, Av = 2.8, ISO = 12800).
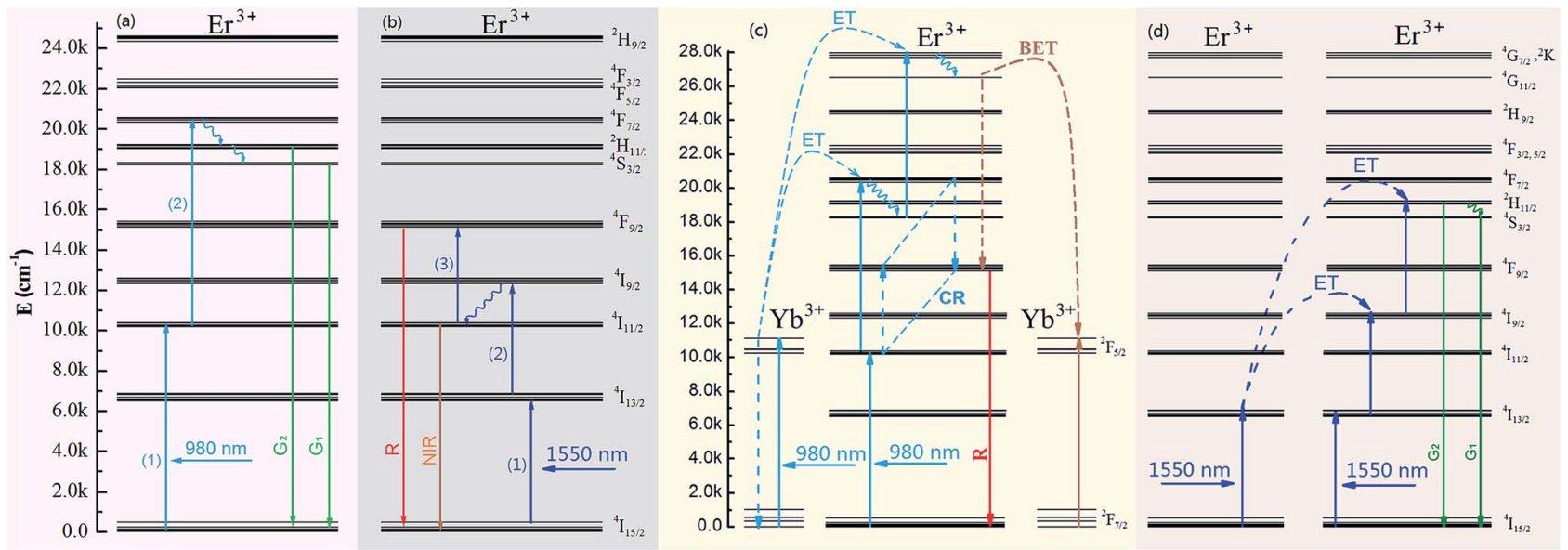

Fig. 3 (a, b) Double-color UCL mechanism of $\mathrm{Er}^{3+}$ under (a) $980 \mathrm{~nm}$-wavelength and (b) $1500 \mathrm{~nm}$-wavelength excitation. (c, d) UCL mechanism of $\mathrm{NaYbF}_{4}: 25 \% \mathrm{Er}^{3+}$ under (c) $980 \mathrm{~nm}$-wavelength and (d) $1500 \mathrm{~nm}$-wavelength excitation. 

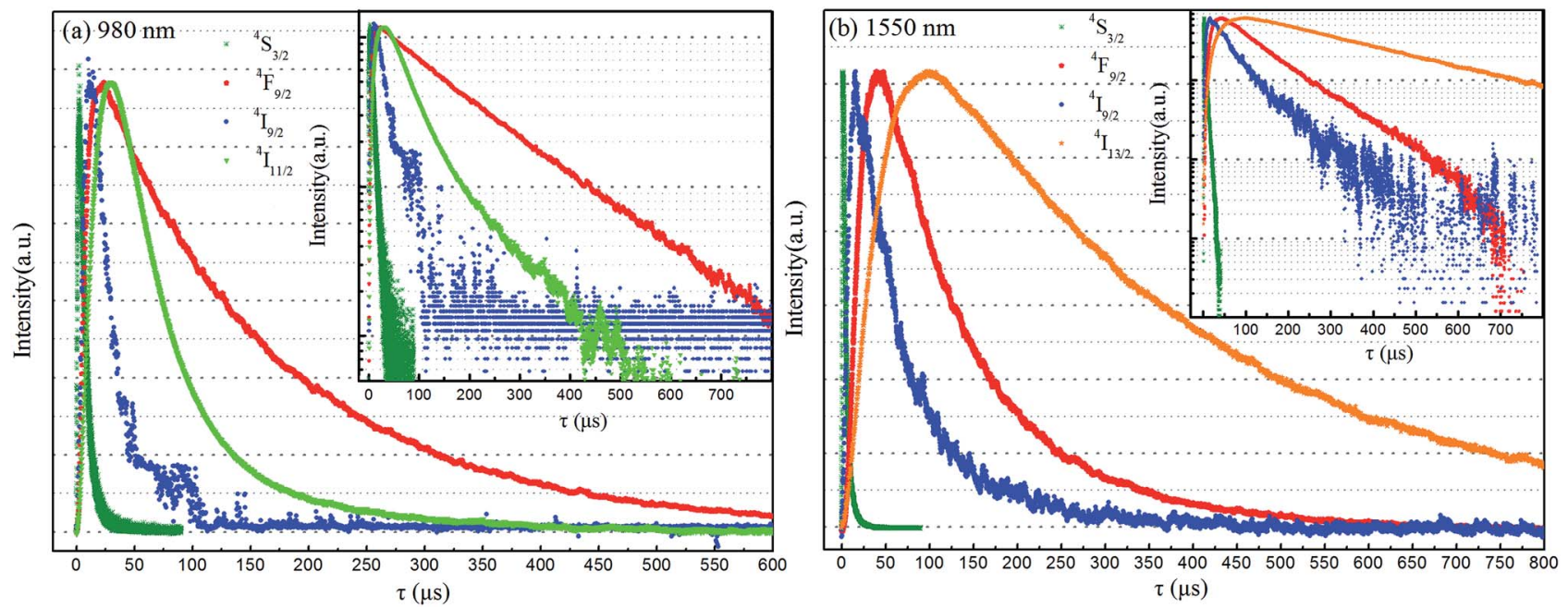

Fig. 4 Decay curves of the $\mathrm{Er}^{3+}{ }^{4} \mathrm{~S}_{3 / 2}(550 \mathrm{~nm}),{ }^{4} \mathrm{~F}_{9 / 2}(654 \mathrm{~nm}),{ }^{4} \mathrm{I}_{9 / 2}(800 \mathrm{~nm}),{ }^{4} \mathrm{I}_{11 / 2}(1000 \mathrm{~nm}),{ }^{4} \mathrm{I}_{13 / 2}(1535 \mathrm{~nm})$ levels in an NaYbF $4: \mathrm{Er}^{3+}$ sample under (a) $980 \mathrm{~nm}$-wavelength and (b) $1550 \mathrm{~nm}$-wavelength pulse LD excitation.

at these two excitation wavelengths. Wei et $a l .^{30}$ attributed the enhancement of red UCL in highly doped $\mathrm{Er}^{3+}$ samples to the cross relaxation (CR, ${ }^{4} \mathrm{~F}_{7 / 2}+{ }^{4} \mathrm{I}_{11 / 2} \rightarrow{ }^{4} \mathrm{~F}_{9 / 2},+{ }^{4} \mathrm{~F}_{9 / 2}$ ) process between $\mathrm{Er}^{3+}$ ions. The CR process was enhanced as the $\mathrm{Er}^{3+}$ concentration was increased, and with increasing $I_{\mathrm{r}} / I_{\mathrm{g}}$ (Fig. S3 $\dagger$ ). However, the $I_{\mathrm{r}} / I_{\mathrm{g}}$ of $\mathrm{Er}^{3+}$-doped $\mathrm{NaYbF}_{4}: x \mathrm{Er}^{3+}$ samples failed to increase as the $\mathrm{Er}^{3+}$ concentration was increased, indicating that the enhancement of red UCL was also related to $\mathrm{Yb}^{3+}$ codoping. ${ }^{31}$ Therefore, the enhancement of red UCL in $\mathrm{NaYbF}_{4}: 25 \% \mathrm{Er}^{3+}$ excited at $980 \mathrm{~nm}$ was due to the combined effect of the CR process and reverse energy transfer from the $\mathrm{Er}^{3+}{ }^{4} \mathrm{G}_{11 / 2}$ level to $\mathrm{Yb}^{3+}$ (Fig. 3c). The green emission displayed by $\mathrm{NaYbF}_{4}: 25 \% \mathrm{Er}^{3+}$ excited with light of a wavelength of $1550 \mathrm{~nm}$ was mainly due to the radiation relaxation ${ }^{4} \mathrm{I}_{9 / 2} \rightarrow$ ${ }^{4} \mathrm{I}_{11 / 2}$ occurring in other host being less likely to take place in $\mathrm{NaYbF}_{4}$ because of the low phonon energy, thus making the energy transfer process $\mathrm{Er}^{3+} \rightarrow \mathrm{Yb}^{3+} \rightarrow \mathrm{Er}^{3+}$ difficult to transpire. $^{32}$ Moreover, the lack of occurrence of the above CR process and the occurrence of weak red emission (Fig. 3d) were due to the difficulty in the ${ }^{4} \mathrm{~F}_{7 / 2}$ level being pumped by light with a wavelength of $1550 \mathrm{~nm}$ (Fig. 4).

\section{Conclusions}

Single-layer spherical $\mathrm{NaYbF}_{4}: 25 \% \mathrm{Er}^{3+}$ UCNPs, with an average particle size of $18 \mathrm{~nm}$, showed double-color emission, of red and green light, under dual-wavelength excitation, of $980 \mathrm{~nm}$ and $1550 \mathrm{~nm}$ wavelengths. In contrast to other methods for achieving multi-color emission from a single sample with complex coating processes, the as-prepared $\mathrm{Er}^{3+}$-doped $\mathrm{NaYbF}_{4}{ }^{-}$ based system is a single-layer structure. And compared with the existing research on multi-color luminescence, the method we have now described involves a simple preparation process, suggesting the potential of achieving mass production. And on this basis, the three primary colors may be expected to be easily achieved by a reasonable designed core-shell.

\section{Conflicts of interest}

There are no conflicts to declare.

\section{Acknowledgements}

The authors thank the Research Program of the National Natural Science Foundation of China (Grant No. 11504039 and 51502031), and the Application Foundation (Main subject) of the Ministry of Transport of PR China (No. 2015329225090). The Fundamental Research Funds for the Central Universities (Grant No. 3132016349 and 3132017061), Program for Liaoning Excellent Talents in University (LR2013020), and Foundation of Liaoning Educational Committee (L2013201, L2014212, L2014208) are also acknowledged for their financial support.

\section{References}

$1 \mathrm{~F}$. Wang and X. G. Liu, Multicolor tuning of lanthanidedoped nanoparticles by single wavelength excitation, Acc. Chem. Res., 2014, 47, 1378-1385.

2 Y. H. Zhang, L. X. Zhang, R. R. Deng, J. Tian, Y. Zong, D. Y. Jin and X. G. Liu, Multicolor barcoding in a single upconversion crystal, J. Am. Chem. Soc., 2014, 136, 48934896.

3 B. Zhou, B. Y. Shi, D. Y. Jin and X. G. Liu, Controlling upconversion nanocrystals for emerging applications, Nat. Nanotechnol., 2015, 10, 924-936.

$4 \mathrm{X}$. Li, R. Wang, F. Zhang and D. Zhao, Engineering homogeneous doping in single nanoparticle to enhance upconversion efficiency, Nano Lett., 2014, 14, 3634-3639.

5 D. J. Gargas, E. M. Chan, A. D. Ostrowski, S. Aloni, M. V. P. Altoe, E. S. Barnard, B. Sanii, J. J. Urban, D. J. Milliron, B. E. Cohen and P. J. Schuck, Engineering bright sub-10-nm upconverting nanocrystals for singlemolecule imaging, Nat. Nanotechnol., 2014, 9, 300-305. 
6 J. J. Zhou, G. X. Chen, E. Wu, G. Bi, B. T. Wu, Y. Teng, S. F. Zhou and J. R. Qiu, Ultrasensitive polarized upconversion of $\mathrm{Tm}^{3+}-\mathrm{Yb}^{3+}$ doped $\beta-\mathrm{NaYF}_{4}$ single nanorod, Nano Lett., 2013, 13, 2241-2246.

7 O. Ehlert, R. Thomann, M. Darbandi and T. Nann, A fourcolor colloidal multiplexing nanoparticle system, ACS Nano, 2008, 2, 120-124.

8 M. L. You, M. Lin, S. R. Wang, X. M. Wang, G. Zhang, Y. Hong, Y. Q. Dong, G. R. Jin and F. Xu, Threedimensional quick response code based on inkjet printing of upconversion fluorescent nanoparticles for drug anticounterfeiting, Nanoscale, 2016, 8, 10096.

9 J. Wang, F. Wang, C. Wang, Z. Liu and X. G. Liu, Single-band upconversion emission in lanthanide-doped $\mathrm{KMnF}_{3}$ nanocrystals, Angew. Chem., Int. Ed., 2011, 50(44), 1036910372.

10 F. Wang and X. G. Liu, Upconversion multicolor fine-tuning: visible to near-infrared emission from lanthanide-doped $\mathrm{NaYF}_{4}$ nanoparticles, J. Am. Chem. Soc., 2008, 130, 56425643.

11 V. Mahalingam, F. Vetrone, R. Naccache, A. Speghini and J. A. Capobianco, Colloidal $\mathrm{Tm}^{3+} / \mathrm{Yb}^{3+}$-Doped $\mathrm{LiYF}_{4}$ nanocrystals: multiple luminescence spanning the UV to NIR regions via low-energy excitation, Adv. Mater., 2009, 21, 4025-4028.

12 H. X. Mai, Y. W. Zhang, L. D. Sun and C. H. Yan, Highly efficient multicolor up-conversion emissions and their mechanisms of monodisperse $\mathrm{NaYF}_{4}: \mathrm{Yb}, \mathrm{Er}$ core and core/ shell- structured nanocrystals, J. Phys. Chem. C, 2007, 111, 13721-13729.

13 J. Zhao, Z. Lu, Y. Yin, C. McRae, J. A. Piper, J. M. Dawes, D. Jin and E. M. Goldys, Upconversion luminescence with tunable lifetime in $\mathrm{NaYF}_{4}: \mathrm{Yb}, \mathrm{Er}$ nanocrystals: role of nanocrystal size, Nanoscale, 2013, 5, 944-952.

14 W. B. Niu, S. L. Wu, S. F. Zhang, J. Li and L. A. Li, Multicolor output and shape controlled synthesis of lanthanide-ion doped fluorides upconversion nanoparticles, Dalton Trans., 2011, 40, 3305-3314.

15 H. Dong, L. D. Sun, Y. F. Wang, J. Ke, R. Si, J. W. Xiao, G. M. Lyu, S. Shi and C. H. Yan, Efficient tailoring of upconversion selectivity by engineering local structure of lanthanides in $\mathrm{Na}_{\mathrm{x}} \mathrm{REF}_{3+\mathrm{x}}$ nanocrystals, J. Am. Chem. Soc., 2015, 137, 6569-6576.

16 G. Chen, H. Liu, G. Somesfalean, H. Liang and Z. Zhang, Upconversion emission tuning from green to red in $\mathrm{Yb}^{3+}$ / $\mathrm{Ho}^{3+}$ - codoped $\mathrm{NaYF}_{4}$ nanocrystals by tridoping with $\mathrm{Ce}^{3+}$ ions, Nanotechnology, 2009, 20, 385704.

17 F. Zhang, Q. Shi, Y. Zhang, Y. Shi, K. Ding, D. Zhao and G. D. Stucky, Fluorescence upconversion microbarcodes for multiplexed biological detection: nucleic acid encoding, Adv. Mater., 2011, 23, 3775-3779.

18 E. M. Chan, G. Han, J. D. Goldberg, D. J. Gargas, A. D. Ostrowski, P. J. Schuck, B. E. Cohen and D. J. Milliron, Combinatorial discovery of lanthanidedoped nanocrystals with spectrally pure upconverted emission, Nano Lett., 2012, 12, 3839-3845.
19 F. Wang, R. Deng, J. Wang, Q. Wang, Y. Han, H. Zhu, X. Chen and X. Liu, Tuning upconversion through energy migration in core-shell nanoparticles, Nat. Mater., 2011, 10, 968-973.

20 E. Downing, L. Hesselink, J. Ralston and R. Macfarlane, A three-color, solid-sate, three- dimensional display, Science, 1996, 273, 1185-1189.

21 H. L. Wen, H. Zhu, X. Chen, T. F. Hung, B. L. Wang, G. Y. Zhu, S. F. Yu and F. Wang, Upconverting nearinfrared light through energy management in core-shellshell nanoparticles, Angew. Chem., Int. Ed., 2013, 52, 13419-13423.

22 R. R. Deng, F. Qin, R. F. Chen, W. Huang, M. H. Hong and X. G. Liu, Temporal full-colour tuning through non-steadystate upconversion, Nat. Nanotechnol., 2015, 10, 237-242.

23 H. Wang, M. M. Xing, X. X. Luo, X. L. Zhou, Y. Fu, T. Jiang, Y. Peng, Y. B. Ma and X. L. Duan, Upconversion emission colour modulation of $\mathrm{Y}_{2} \mathrm{O}_{2} \mathrm{~S}$ : $\mathrm{Yb}$, Er under $1.55 \mu \mathrm{m}$ and 980 nm excitation, J. Alloys Compd., 2014, 587, 344-348.

24 S. Fischer, B. Frohlich, K. W. Kramer and J. C. Goldschmidt, Relation between excitation power density and $\mathrm{Er}^{3+}$ doping yielding the highest absolute upconversion quantum yield, J. Phys. Chem. C, 2014, 118, 30106-30114.

25 X. M. Yin, H. Wang, M. M. Xing, Y. Fu, Y. Tian, T. Jiang and $\mathrm{X}$. X. Luo, High color purity red emission of $\mathrm{Y}_{2} \mathrm{Ti}_{2} \mathrm{O}_{7}: \mathrm{Yb}^{3+}, \mathrm{Er}^{3+}$ under 1550 and $980 \mathrm{~nm}$ excitation, $J$. Lumin., 2017, 182, 183-188.

26 H. Wang, T. Jiang, M. M. Xing, Y. Fu, Y. Peng and X. X. Luo, $\mathrm{Up}$ - conversion luminescence of $\mathrm{Y}_{2} \mathrm{O}_{3}: \mathrm{Yb}$, Er under $1.55 \mu \mathrm{m}$ excitation, Ceram. Int., 2015, 41, 259-263.

27 W. Shao, G. Y. Chen, J. Damasco, X. L. Wang, A. Kachynski, T. Y. Ohulchanskyy, C. H. Yang, H. Agren and P. N. Prasad, Enhanced upconversion emission in colloidal $\left(\mathrm{NaYF}_{4}: \mathrm{Er}^{3+}\right) /$ $\mathrm{NaYF}_{4}$ core/shell nanoparticles excited at $1523 \mathrm{~nm}$, Opt. Lett., 2014, 39, 1386-1389.

28 H. Wang, X. M. Yin, M. M. Xing, Y. Fu, Y. Tian, X. Feng, T. Jiang and X. X. Luo, Investigation on the thermal effects of $\mathrm{NaYF}_{4}: \mathrm{Er}$ under $1550 \mathrm{~nm}$ irradiation, Phys. Chem. Chem. Phys., 2017, 19, 8465-8470.

29 G. Y. Chen, T. Y. Ohulchanskyy, A. Kachynski, H. Agren and P. N. Prasad, Intense visible and near-infrared upconversion photoluminescence in colloidal $\mathrm{LiYF}_{4}: \mathrm{Er}^{3+}$ nanocrystals under excitation at $1490 \mathrm{~nm}$, ACS Nano, 2011, 5, 4981-4986.

30 W. Wei, Y. Zhang, R. Chen, J. L. Goggi, N. Ren, L. Huang, K. K. Bhakoo, H. Sun and T. T. Y. Tan, Cross relaxation induced pure red upconversion in activator- and sensitizerrich lanthanide nanoparticles, Chem. Mater., 2014, 26, 5183-5186.

31 M. T. Berry and P. S. May, Disputed mechanism for NIR-toRed upconversion luminescence in $\mathrm{NaYF}_{4}: \mathrm{Yb}^{3+}, \mathrm{Er}^{3+}, J$. Phys. Chem. A, 2015, 119, 9805-9811.

32 X. L. Shen, M. M. Xing, Y. Tian, Y. Fu, Y. Peng and X. X. Luo, Upconversion photoluminescence properties of $\mathrm{SrY}_{2} \mathrm{O}_{4}: \mathrm{Er}^{3+}, \mathrm{Yb}^{3+}$ under 1550 and $980 \mathrm{~nm}$ excitation, J. Rare Earths, 2016, 34, 458-463. 